\title{
Sébastien Arfouilloux, Que la nuit tombe sur l'orchestre. Surréalisme et musique
}

\section{Marcella Biserni}

\section{(2) OpenEdition}

1 Journals

\section{Edizione digitale}

URL: http://journals.openedition.org/studifrancesi/6082

DOI: $10.4000 /$ studifrancesi.6082

ISSN: 2421-5856

\section{Editore}

Rosenberg \& Sellier

\section{Edizione cartacea}

Data di pubblicazione: 1 mai 2011

Paginazione: 208-209

ISSN: 0039-2944

\section{Notizia bibliografica digitale}

Marcella Biserni, «Sébastien Arfouilloux, Que la nuit tombe sur l'orchestre. Surréalisme et musique», Studi Francesi [Online], 163 (LV | I) | 2011, online dal 30 novembre 2015, consultato il 12 janvier 2021. URL: http://journals.openedition.org/studifrancesi/6082 ; DOI: https://doi.org/10.4000/studifrancesi.6082

Questo documento è stato generato automaticamente il 12 janvier 2021.

\section{(c) $(1) \&$}

Studi Francesi è distribuita con Licenza Creative Commons Attribuzione - Non commerciale - Non opere derivate 4.0 Internazionale. 


\title{
Sébastien Arfouilloux, Que la nuit tombe sur l'orchestre. Surréalisme et musique
}

\author{
Marcella Biserni
}

\section{NOTIZIA}

SÉBASTIEN ARFOUILLOUX, Que la nuit tombe sur l'orchestre. Surréalisme et musique, Paris, Fayard, 2009 («Les chemins de la musique»), pp. 485.

1 La musica ha attraversato il Surrealismo? Attorno a questa domanda il testo, suddiviso analiticamente in quattro parti e dodici capitoli, ripercorre la storia del gruppo parigino, risalendo ai suoi predecessori o ispiratori: Apollinaire, De Chirico, i dadaisti seguaci di T. Tzara fino a citarne i precursori Lautréamont e Rimbaud. L'enorme quantità di informazioni riportate, tratte scientificamente dai manifesti, dalle dichiarazioni e soprattutto dalle opere degli esponenti che gravitarono nell'orbita del movimento, spazia dal campo della poesia e delle arti figurative a quello musicale.

2 La possibilità dell'esistenza di una musica puramente surrealista fa da perno alle riflessioni di Arfouilloux e al contempo rianima diatribe insite nel gruppo, seppur sconfinanti in altri ambiti. Breton e i suoi si domandarono per lungo tempo se, come in poesia, si potesse creare un dipinto o scrivere un romanzo in grado di riprodurre il moto rapido e interiore dell'inconscio o la visionarietà del sogno. Se però la pittura e il romanzo riuscirono più o meno a conciliarsi con le idee del movimento, la musica non ebbe lo stesso "fortunato" destino, restando così ai margini dell'onda surrealista.

3 L'A., fin dalla prima parte, tenta di fornire delle spiegazioni ricostruendo l'interesse musicale dei surrealisti per la musica e dei musicisti per il Surrealismo. In primis si concentra sulla figura di E. Satie che considera una «préfiguration» (p. 20) del Dadaismo, con il quale la sua opera si intrecciò più volte. Nel 1917 collabora con Cocteau alla rappresentazione di Parade a partire dalla quale Apollinaire conia il 
termine surréalisme in riferimento a un tipo di realismo reazionario, che poi solo con Breton troverà un nuovo impulso.

4 Nella seconda e nella terza parte il testo evidenzia le motivazioni del rifiuto e contemporaneamente l'attrazione dei surrealisti verso l'ambito sonoro. Sulla base di citazioni e di rimandi alle opere dei componenti del gruppo parigino e in particolare di Breton vengono messi in luce i concetti cardine espressi nel Manifesto del 1924 e rivisitati in ogni forma d'arte: pittura, poesia, cinema. Si scopre così che se per Breton, privo di orecchio musicale, non era possibile che la musica raggiungesse le vette dell'automatismo psichico, esisteva però intrinsecamente alla concezione surrealista una musicalità poetica, tramandata da Rimbaud, che si avvicinava al canto e che ritrovava nella canzone i principi del gioco e dell'improvvisazione. Inoltre, lontano dall'egemonica presenza bretoniana le "incursioni" di alcuni componenti in ambito jazz si fanno strada, aprendo le porte alle note di origine africana, lontane dal centralismo occidentale e pronte al rovesciamento dei valori estetici.

5 Nell'ultima sezione la tesi che la musica sia parte integrante dell'esprit surrealista è confermata apertamente e sostenuta da esempi concreti che vanno da F. Poulenc a A. Souris, da A. Savinio a G. Antheil. Ed è in particolare nelle teorizzazioni e nelle sperimentazioni di matrice belga, di P. Nougé in letteratura, di R. Magritte in arte e di Souris in musica, e nella loro creazione collettiva che le parole scavalcano la loro funzione referenziale e trovano l'espressione del suono e dell'immagine nell'unico intento di "sconvolgere" il reale. 